\title{
I - Philippe Goujard (1946-2008)
}

\section{Michel Biard}

\section{(2) OpenEdition}

\section{Journals}

\section{Édition électronique}

URL : https://journals.openedition.org/ahrf/10753

DOI : $10.4000 /$ ahrf.10753

ISSN : $1952-403 X$

Éditeur :

Armand Colin, Société des études robespierristes

Édition imprimée

Date de publication : 1 janvier 2009

Pagination : 205-206

ISBN : 978-2-200-92557-4

ISSN : 0003-4436

Référence électronique

Michel Biard, «I - Philippe Goujard (1946-2008) », Annales historiques de la Révolution française [En ligne], 355 I janvier-mars 2009, mis en ligne le 01 janvier 2012, consulté le 22 avril 2022. URL : http:// journals.openedition.org/ahrf/10753 ; DOI : https://doi.org/10.4000/ahrf.10753 
H O M M A G

\section{PHILIPPE GOUJARD (1946-2008)}

Philippe Goujard, membre de la Société des études robespierristes, nous a quittés, laissant ses collègues de l'Université de Rouen orphelins de sa forte personnalité qui ne pouvait laisser indifférent, de son immense culture et de ses interventions toujours pleines d'humour. Même si ses recherches l'avaient parfois éloigné de la Révolution française, il était un lecteur assidu des $A H R F$, donnait aussi à notre revue des comptes rendus (ainsi celui publié dans le $\mathrm{n}^{\circ} 1$-2007) et n'hésitait jamais à me faire part de ses remarques sur tel article ou tel autre texte publiés. Dans cette Université de Rouen où existe de longue date une solide tradition des études révolutionnaires, il a toujours participé avec enthousiasme aux colloques, journées d'études et séminaires qui concernaient la Révolution française. Son esprit critique toujours en alerte était alors précieux dans nos débats, ce même esprit qu'il a essayé de transmettre à des générations successives d'étudiants et qu'il estimait indissociable du métier d'historien. Récemment, dans notre séminaire, il avait donné une communication d'une grande richesse sur le despotisme éclairé, objet de ses travaux en cours. Même affaibli par la maladie, il avait tenu ces derniers temps à poursuivre son travail d'écriture, à se consacrer à la nouvelle question d'agrégation qui passionnait le grand connaisseur de l'histoire religieuse des Temps modernes qu'il était devenu, mais aussi à participer aux réunions du département d'histoire notamment afin d'y pourfendre ce qu'il nommait la « contre-réforme » du Capes. L'ombre de sa silhouette toujours élégante planera longtemps dans le bâtiment Robespierre de notre UFR, lieu où se donnent les cours et TD d'histoire.

Tous ses collègues de Rouen, notamment les spécialistes de la Révolution française et membres de la Société des études robespierristes qui y ont enseigné ou y enseignent encore (Claude Mazauric, Guy Lemarchand, Jean-Pierre Jessenne, Christine Le Bozec, Pascal Dupuy, Bernard Bodinier, Éric Wauters, Éric Saunier, Danièle Pingué et moi-même) sont 
aujourd'hui affligés de cette perte. Les $A H R F$ ont tenu à publier les deux textes ci-dessous qui ont été lus le 21 décembre dernier, au cimetière Saint-Sever de Rouen, lors de l'inhumation de Philippe.

Michel BIARD

Professeur à l'Université de Rouen 